\title{
TPS Nanocomposite Reinforced with MFC by Melting Process
}

\author{
Adriane Medeiros Ferreira ${ }^{a}$, Antonio José Felix Carvalho ${ }^{a *}$ \\ ${ }^{a}$ Departamento de Engenharia de Materiais, Escola de Engenharia de São Carlos, \\ Universidade de São Paulo - USP, Av. Trabalhador São carlense, 400, CEP 13566-590, São Carlos, SP, Brazil
}

Received: April 4, 2013; Revised: January 12, 2014

\begin{abstract}
Bionanocomposites of thermoplastic starch (TPS) reinforced with microfibrilated cellulose (MFC) were prepared by melt processing. MFC was prepared from eucalyptus wood pulp by a process combining cryogenic milling in high shear mixers, chemical treatment with sodium hydroxide and ultrasound treatment. The never dried MFC was then dispersed in native starch and glycerol and processed in a single screw extruder. Two MFC contents were incorporated, 3 and $10 \mathrm{wt} \%$, based on TPS. The MFC was characterized by atomic force microscopy (AFM) and scanning electron microscopy (SEM). The bionanocomposites were characterized by tensile tests, SEM and water absorption experiments. Modulus and tensile strength were improved. Water absorption did not change in an appreciable way with the addition of MFC. The homogeneous dispersion of the MFC into TPS matrix can be considered one of the remarkable points of the new process used in the composite preparation.
\end{abstract}

Keywords: bionanocomposites, microfibrilated cellulose, thermoplastic starch (TPS)

\section{Introduction}

Nanocomposites produced integrally from biodegradable and renewable materials are of great interest due to their potential uses in several new applications. Among the materials studied, thermoplastic starch (TPS) and microfibrillated cellulose (MFC) are considered of special importance due to the low cost of TPS and high availability of cellulose, but two drawbacks need to be considered, namely the preparation of MFC which needs complex and energy demanding processing and its inclusion into thermoplastic matrix avoiding its high tendency to form agglomerates.

The applications of cellulosic nanomaterials such as cellulose nanocrystals and microfibrillated cellulose have been described recently ${ }^{1-3}$, which allow the preparation of materials with better optical and mechanical properties due to the strength, low weight and nanometric nature of the reinforcement filler.

MFC is extracted from the cellulose cell wall by intensive process and shows dimension in its diameter from 2 to $20 \mathrm{~nm}$ and length of up to micrometers, which depend on the plant source ${ }^{4-6}$. The preparation of MFC has been studied by several groups and the most employed methods for MFC preparation call upon the homogenization in high pressure and energy consumption equipments such as Monton Gaulin homogenizers ${ }^{3,7}$. New methods, such as cryogenic milling based on the crystallization of water between the cellulose fiber tissue, which separates the microfibrils, and ultrasound treatment have gained importance ${ }^{4}$.

Nanocellulose composites have been prepared most frequently by casting a suspension of gelatinized starch and the nanocellulose filler ${ }^{2,3}$, a process that limits its application.

*e-mail: toni@sc.usp.br
In this study, MFC was prepared from Kraft eucalyptus bleached wood pulp using a combination of chemical treatment with $\mathrm{KOH}$ and high shear dispersion combined with ultrasound. The never dried cellulose was then mixed with native starch and processed directly in an extruder where starch destructuration and cellulose dispersion occurred at the same time. The water present in MFC helps starch destructuration since water is a plasticizer for starch.

\section{Experimental}

\subsection{Materials}

Regular corn starch (28\% amylose) with $11 \%$ moisture was obtained from Corn Products Brazil. Reagent grade ascorbic acid and glycerol from Synth-Brazil were used as received. Bleached eucalyptus Kraft wood pulp was provided by Suzano Pulp and Paper SA, Bahia unit.

\subsection{Preparation of microfibrilated cellulose (MFC)}

$140 \mathrm{~g}$ of Kraft cellulose pulp from eucalyptus was dried and milled in a Wiley mill. The milled pulp was treated with a 2 wt. $\%$ aqueous $\mathrm{KOH}$ solution at $80 / 90{ }^{\circ} \mathrm{C}$ for $2 \mathrm{~h}$, under magnetic stirring and isolated from the $\mathrm{KOH}$ solution by filtration employing a Buchner funnel with polyester nonwoven tissue filter. The pulp was washed with distilled water for complete removal of the $\mathrm{KOH}$ solution until neutral $\mathrm{pH}$ as determined by $\mathrm{pH}$ indicator strips.

The pre-treated pulp was weighed and dispersed in water with a Turrax high shear homogenizer at 20,000 rpm for 50 s. The resulting suspension was subjected to sonication in an ultrasound bath for $10 \mathrm{~min}$. 


\subsection{Nanocomposite preparation}

The appropriate amount of native starch was then dispersed in the cold MFC water suspension and the mixture dried in an air circulation oven at $60{ }^{\circ} \mathrm{C}$ for $48 \mathrm{~h}$ and then in a vacuum oven at $80{ }^{\circ} \mathrm{C}$ for an additional $48 \mathrm{~h}$. The dried material was mixed with glycerol so that the final proportion of starch/glycerol was 70:30. The resulting material was a powder and was fed directily into the extruder by a crammer feeder hopper. The compositions of the mixtures are given in Table 1. The procedure used for the addition of MFC into TPS was similar to that used in previous work ${ }^{8,9}$.

\subsection{Extrusion processing}

The mixtures of starch, glycerol and MFC was processed in a single screw extruder with a $16 \mathrm{~mm}$ screw $(\mathrm{L} / \mathrm{D}=40)$ operating at $31 \mathrm{rpm}$ at the following temperatures from feed to die zone, $110,120,120$ and $110^{\circ} \mathrm{C}$, respectively. The extruded mateial was hot pressed at $150{ }^{\circ} \mathrm{C}$ into $2 \mathrm{~mm}$ thick plates.

\section{Materials Characterization}

\subsection{Atomic Force Microscopy (AFM)}

Atomic force microscopy images were obtained with a Digital/Veeco AFM model Nanoscope IIIa. The samples were prepared by placing a drop of diluted aqueous MFC suspension over fresh cleaved mica, which was subsequently dried on a heater plate.

\subsection{Scanning Electron Microscopy (SEM-FEG)}

SEM images were taken with a Philips Scanning Electron microscopy, model, XL30-FEG. Samples were prepared by dropping dilute aqueous suspensions of the MFC over freshly cleaved mica, which were subsequently dried by heating on a hot plate and then bonded on aluminum tips. The samples were covered with a thin layer of gold ( $<10 \mathrm{~nm}$ ) by sputtering.

\subsection{Tensile tests}

Tensile tests were performed according to ASTM D638 at a rate of strain of $50 \mathrm{~mm} / \mathrm{min}$ in a universal testing machine EMIC-Brazil, model DL-10000 working with 5 $\mathrm{kg}$ load cell. Specimens were conditioned for 10 days at $25 \pm 1{ }^{\circ} \mathrm{C}$ and at $53 \%$ relative air humidity $(\mathrm{RH})$. For each measurement, at least 8 specimens of each sample were tested. The result was an average of the results. Results very far from the average were discarded.

\subsection{Water absorption (WA)}

Samples were cut in a circular form with $11 \mathrm{~mm}$ diameter and $2 \mathrm{~mm}$ thickness and dried at $110 \pm 1^{\circ} \mathrm{C}$ up to

Table 1. Composition code names, MFC content and mechanical and water absorption properties of the matrix and nanocomposite materials.

\begin{tabular}{cccccc}
\hline \multirow{2}{*}{$\begin{array}{c}\text { Sample } \\
\text { identification }\end{array}$} & $\begin{array}{c}\text { MFC content } \\
\text { wt \% }\end{array}$ & Modulus (MPa) & $\begin{array}{c}\text { Tensile strength } \\
\text { (MPa) }\end{array}$ & $\begin{array}{c}\text { Maximum elongation } \\
\text { at break (\%) }\end{array}$ & $\begin{array}{c}\text { Water Absorption } \\
\text { 75\% U.R. }\end{array}$ \\
\cline { 5 - 6 } & 0 & $27.0 \pm 2.1$ & $3.5 \pm 0.2$ & $35.1 \pm 0.6$ & 22.0 \\
TPS-G30 & 3 & $29.0 \pm 1.0$ & $4.5 \pm 0.2$ & $31.7 \pm 0.6$ & 21.4 \\
TPS-G30-MFC 3 & 10 & $55.6 \pm 0.9$ & $6.1 \pm 0.9$ & $16.8 \pm 0.9$ & 21.2 \\
\hline
\end{tabular}

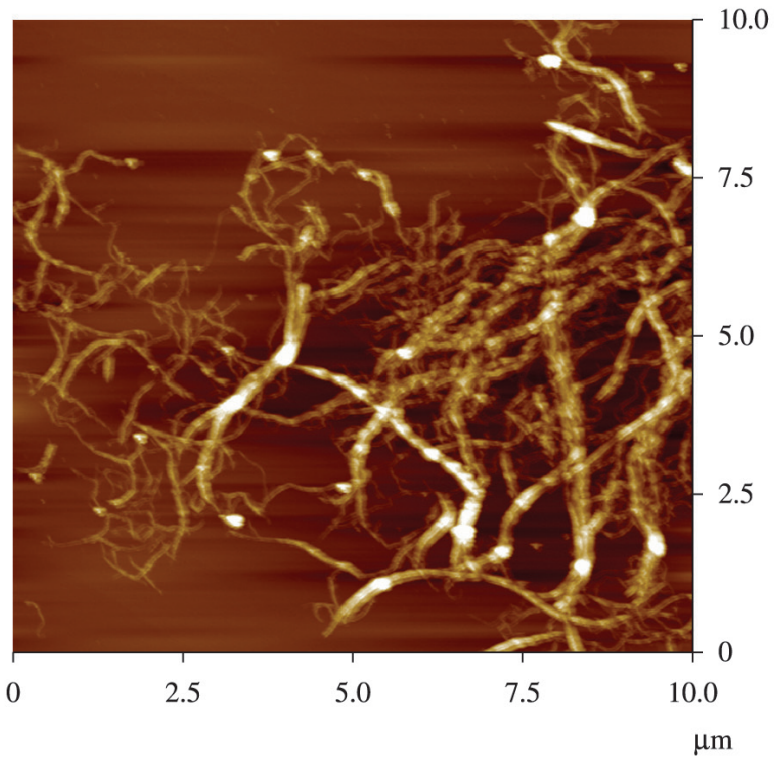

(a)

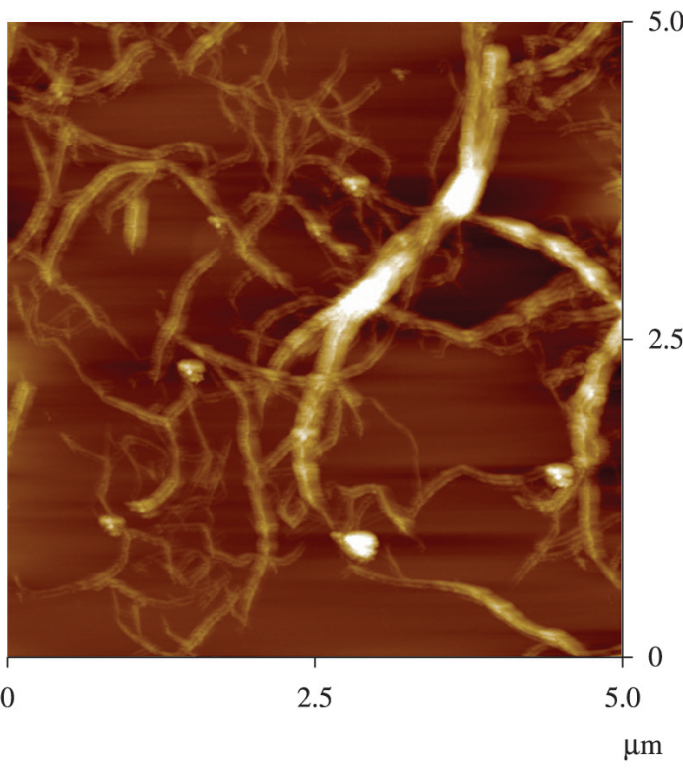

(b)

Figure 1. AFM height images cellulose microfibrils on mica substrate, (a) $10 \times 10 \mathrm{~mm}$ and (b) and $5 \times 5 \mathrm{~mm}$. 


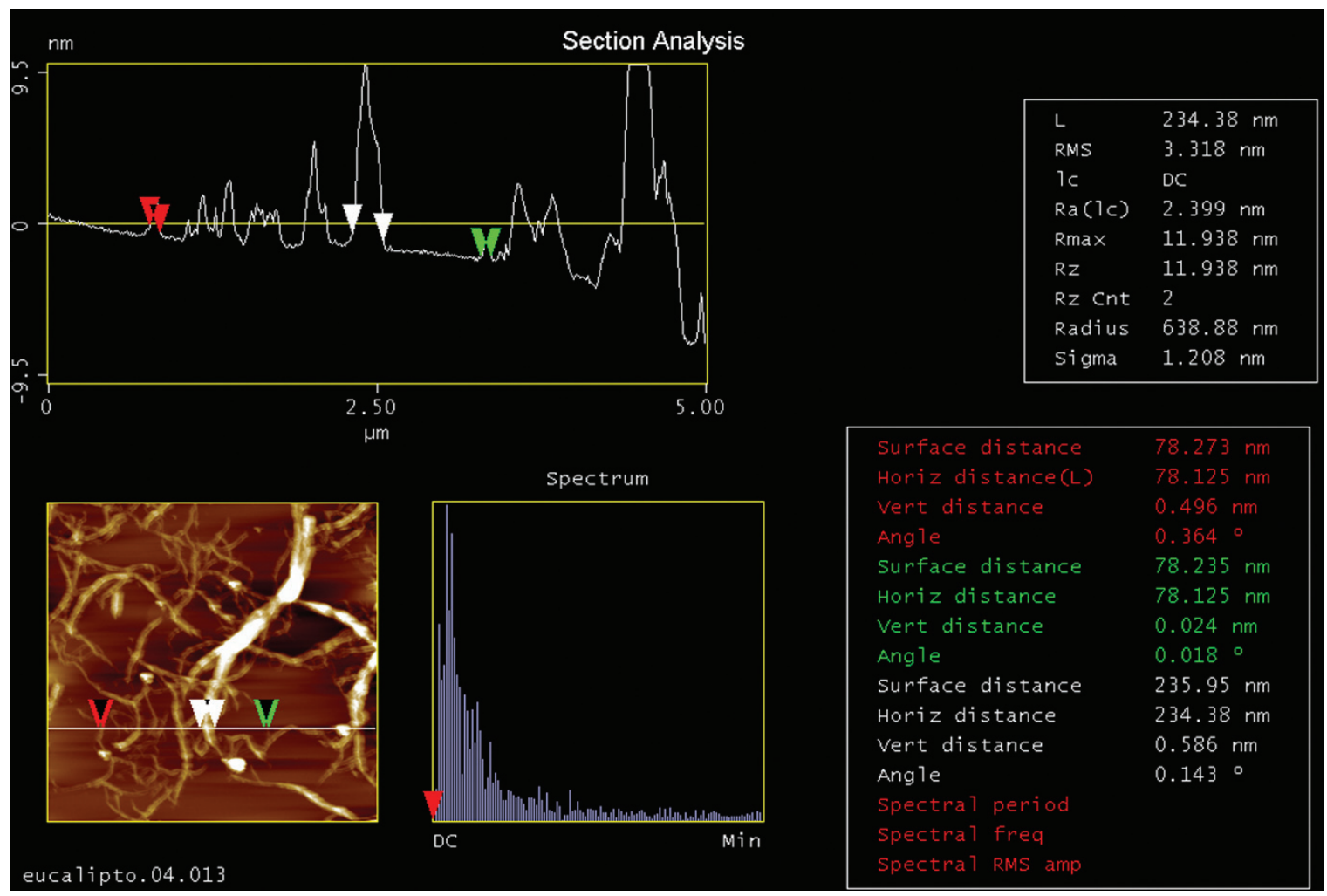

Figure 2. Microfibril profiles by AMF with diameter varying from 78 to $235 \mathrm{~nm}$.

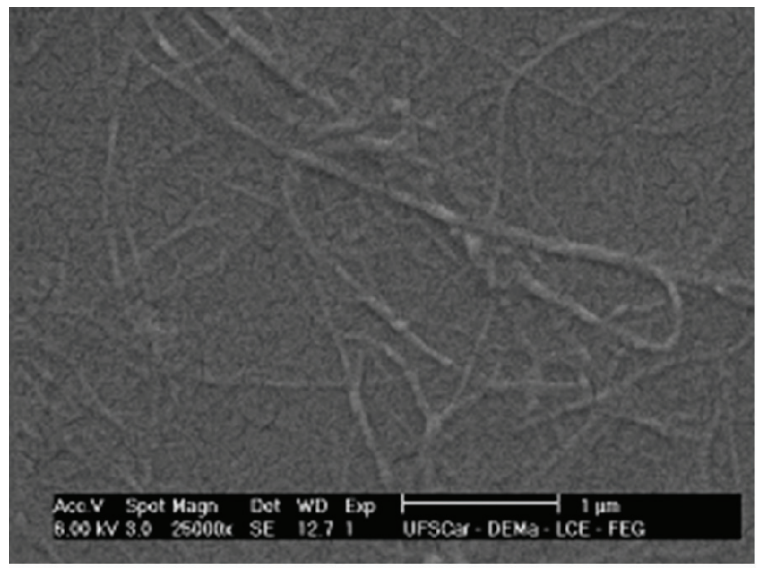

(a)

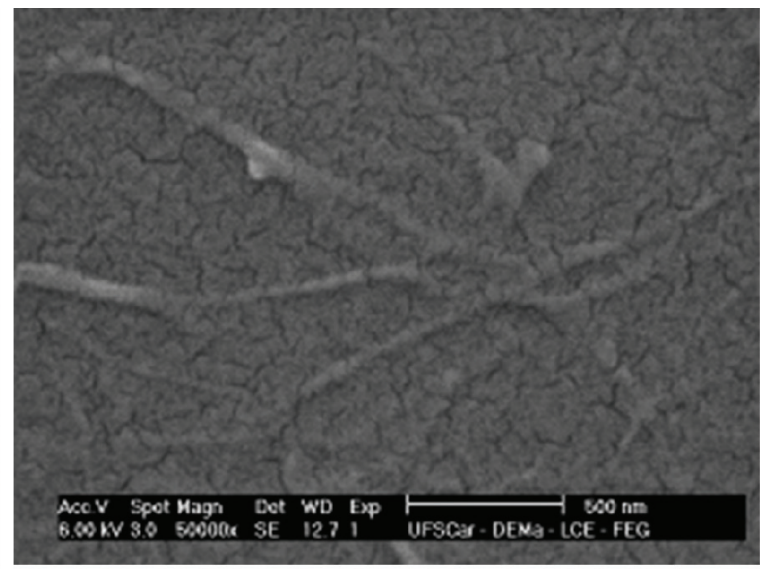

(b)

Figure 3. SEM micrographs of cellulose microfibrils with magnifications of (a) $25,000 \times$ and (b) and 50,000 $\times$.

constant weight prior to water absorption experiments. The samples were then conditioned in containers with relative humidity of 53 and $97 \%$, at $25 \pm 2{ }^{\circ} \mathrm{C}$. The relative humidity environment was produced with saturated solutions of $\mathrm{NaCl}$, following ASTM E-104. The amount of water absorbed was measured by weighing the samples until constant mass.

\section{Results and Discussion}

AFM and SEM images of the microfibrilated cellulose are showed in Figure 1 and 3, respectively. These images produced from cellulose suspension deposited on mica substrates confirm the formation of microfibrillated cellulose with diameter at nanometer scale and length of microns. Figure 2, shows the profile obtained from the AFM image showed in Figure 1. In the analyzed portion of the samples, the MFC shows diameters varying from approximately 80 to $200 \mathrm{~nm}$. These samples are representative of most of the material produced by the defibrillation using $\mathrm{KOH}$ extraction and dispersion with high shear mixing and ultrasound.

The data for MFC content of the thermoplastic materials are shown in Table 1. The mixing efficiency of MFC into 


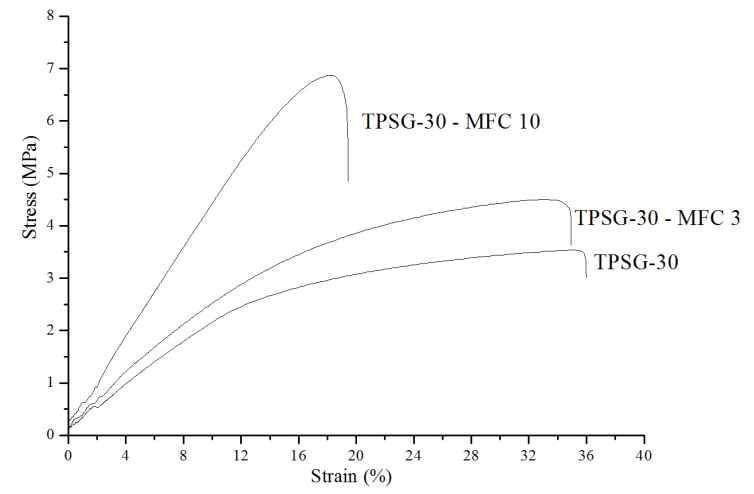

Figure 4. Stress vs. strain curve for nanocomposites with A) 0.0, B) and C 3.0) $10.0 \%$ of microfibrils.

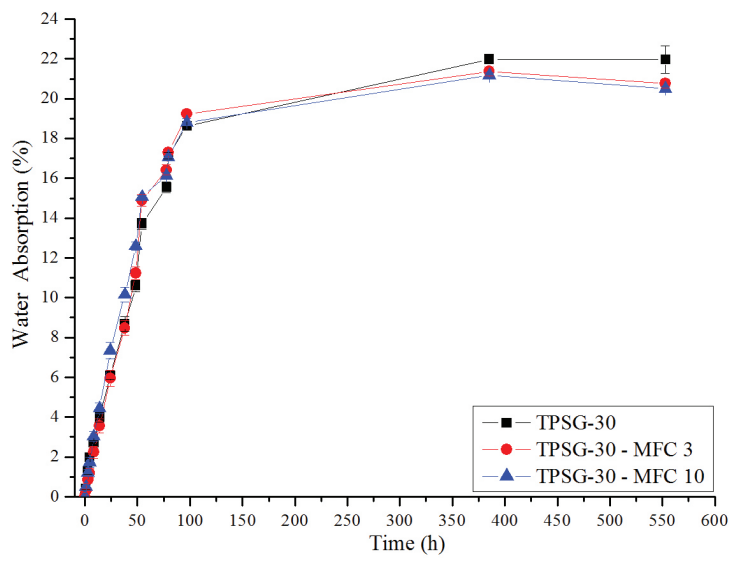

Figure 5. Water absorption curves as a function of conditioning time for different materials in an environment of relative humidity of (a) 43 , (b) and 53 (c) $75 \%$.

TPS matrix was very satisfactory up to $10 \mathrm{wt} \%$. Higher content were not produced since $10 \mathrm{wt} \%$ is a very high quantity of filler considering the low density of cellulose and the nanometric nature of the filler. The extruded material was very homogeneous and thin plates produced by hot

1. Denchev ZZ, Dencheva NV. Transforming polymer blends into composites: a pathway towards nanostructured materials. Polymer International. 2008; 57:11-22. http://dx.doi. org/10.1002/pi.2283

2. Dufresne A, Cavaillé JY, Vignon MR. Mechanical behavior of sheets prepared from sugar beet cellulose microfibrils. Journal of Applied Polymer Science. 1997; 64:1185-1194. http://dx.doi. org/10.1002/(SICI)1097-4628(19970509)64:6<1185::AIDAPP19>3.0.CO;2-V

3. Dufresne A, Vignon MR. Improvement of starch film performances using cellulose microfibrils. Macromolecules. 1998; 31: 2693-2696. http://dx.doi.org/S0024-9297(97)015325

4. Chen W, Yu HP, Liu YX, Chen P, Zhang MX and Hai YF. Individualization of cellulose nanofibers from wood using high-intensity ultrasonication combined with chemical pretreatments. Carbohydrate Polymers. 2011; 83:1804-1811. http://dx.doi.org/10.1016/j.carbpol.2010.10.040

5. Moon RJ, Martini A, Nairn J, Simonsen J and Youngblood J. Cellulose nanomaterials review: structure, properties and nanocomposites. Chemical Society Reviews. 2011; 40:39413994. http://dx.doi.org/10.1039/c0cs00108b pressing were free of cellulose agglomerates, which confirm the efficiency of the used procedure.

Representative curves of the tensile-strength tests are displayed in Figure 4. The reinforcing effect as the fiber content is increased is quite clear. The data for modulus, tensile trenght and elongation at break are given in Table 1. Tensile strenght of the composite with $10 \mathrm{wt} \%$ of MFC was increased by $60 \%$ with respect to the TPS matrix.

The water absorption curves are shown in Figure 5 and the data for the absorbed water at the equilibrium appear in Table 1. The curves in Figure 5 show that equilibrium is reached after 100/150 h approximately. One interesting result is the fact that the MFC did not affect water absorption in opposition to the results obtained for similar material produced with wood pulp instead of $\mathrm{MFC}^{8,9}$.

\section{Conclusions}

The process for the preparation of MFC combining $\mathrm{KOH}$ extraction and homogenization by high shear mixing and ultrasound was effective in producing nanometric wood fibers from eucalyptus pulp. The dispersion of never dried MFC into TPS matrix by its mixing with native starch and glycerol followed by extrusion processing was effective, generating the homogeneous composites free of cellulose agglomerates. MFC improved the mechanical properties of TPS composites by doubling the modulus and tensile strength. Water absorption at equilibrium was not affected by the presence of MFC.

\section{Acknowledgments}

This work was supported by the State of São Paulo Research Foundation (FAPESP) and the National Council for Scientific and Technological Development (CNPq) The authors acknowledge the Brazilian Synchrotron Light Laboratory by the SEM and AFM images.

\section{References}

6. Siró I, Plackett D. Microfibrillated cellulose and new nanocomposite materials: a review. Cellulose. 2010; 17:459494. http://dx.doi.org/10.1007/s10570-010-9405-y

7. Orts WJ, Shey J, Imam SH, Glenn GM, Guttman ME and Revol JF. Application of cellulose microfibrils in polymer nanocomposites. Journal of Polymers and the Environment. 2005; 13:301-306. http://dx.doi.org/10.1007/s10924-005$5514-3$

8. Carvalho AJF, Curvelo AAS, Agnelli AM. Wood Pulp Reinforced Thermoplastic Starch Composites. International Journal of Polymeric Materials. 2000; 1-16. http://dx.doi. org/10.1080/714975803

9. Curvelo AAS, Carvalho AJF, Agnelli AM. Thermoplastic starch-cellulosic Fibers composites: preliminary results. Carbohydrate Polymers. 2001; 45:183-188. http://dx.doi. org/10.1016/S0144-8617(00)00314-3 